04

\title{
3D защитный голографический элемент с криптографической информацией
}

\author{
(C) Е.Б. Шекланова, М.И. Фокина, И.Ю. Денисюк \\ Университет ИТМО, \\ 197101 Санкт-Петербург, Россия \\ e-mail: e.sheklanova@corp.ifmo.ru
}

Поступила в редакцию 07.05.2018 г.

Рассмотрены защитные элементы, сформированные в $3 D$-голограмме, записанной в полимерном нанокомпозите: голограмма линзы, голограмма линзы с записанной на ней криптографической информацией, голограмма, содержащая не видимое глазом скрытое криптографическое изображение, пропускающий элемент на основе объемной голограммы плоского объекта. Голограммы записаны на нанокомпозиционном материале, представляющем собой фотополимеризующуюся мономерную композицию и содержащем различные фотосенсибилизаторы и наночастицы.

DOI: $10.21883 /$ OS.2018.10.46708.127-18

Среди регистрирующих сред для голографии можно выделить голографические фотополимеры, обладающие рядом преимуществ, например, высокая скорость записи, отсутствие химической обработки после экспонирования и другими. Запись изображения в таких материалах, обусловлена фотостимулированной модуляцией показателя преломления, последнее достигается обычно перемещением компонент фотополимеризующейся композиции под действием излучения. Так, в работе [1] рассмотрены основные процессы формирования модуляции показателя преломления в фотополимерах. Общим недостатком всех голографических фотополимеров традиционного типа является малое различие между показателем преломления мономера и связки, и как результат - необходимость использования достаточно толстых, до $100 \mu \mathrm{m}$, слоев для достижения дифракционной эффективности, близкой к $100 \%$.

Голографические нанокомпозиционные материалы основаны на тех же принципах формирования решетки, записанной в объеме и основанной на разделении компонентов композиции, что и традиционные фотополимеры. Однако транспортируемым компонентом, существенно увеличивающим модуляцию показателя преломления при фотоиндуцированном перемещении в материале, являются введенные неорганические высокорефрактивные наночастицы. Начало этому направлению дала работа [2], в которой рассмотрен фотополимеризующийся голографический материал с наночастицами $\mathrm{TiO}_{2}$.

Возможная область применения подобных материалов - изготовление защитных голографических элементов на основе объемных (3D) голограмм, допускающих персонализацию путем введения в них портретов, надписей или иных признаков, связанных с конкретным владельцем защищаемого от подделки документа или предмета.

В данной статье рассмотрено применение разработанного ранее акрилатного нанокомпозита $[3,4]$ для записи голографического защитного $3 D$-элемента, несущего дополнительные криптографические изображения. Голографический материал представляет собой жидкую фоточувствительную мономерную композицию и содержит фотосенсибилизаторы и наночастицы $\mathrm{SiO}_{2}$ диаметром 5-15 nm. Для настоящей работы использовались следующие мономеры: 2-Carboxyethyl acrylate (Aldrich № 552348, 2Car); Bisphenol A glycerolate (1 glycerol/phenol) diacrylate (Aldrich № 411167, Bis); 1,6-Hexanediol diacrylate (Aldrich № 13048-33-4, DIOL); Diuretane dimetilacrilate (Aldrich № 436909, UDMA). Также в состав входил фотоинициатор Irgacure 784-Bis (eta 5-2,4-cyclopentadien-1-yl) Bis [2,6-difluoro-3-(1H-pyrrol-1-yl)phenyl]titanium. Фотоинициатор Irgacure 784 (Irg) обеспечивает чувствительность в спектральной области от 400 до $550 \mathrm{~nm}$. Принцип записи основан на перераспределении компонентов материала под действием излучения при фотополимеризации акрилового мономера. Заданное периодическое распределение света вызывает перемещение компонентов системы, образуя периодическое изменение показателя преломления в объеме материала. Как показано в работе [5], материал пригоден для записи на нем дифракционных оптических элементов голографическим методом.

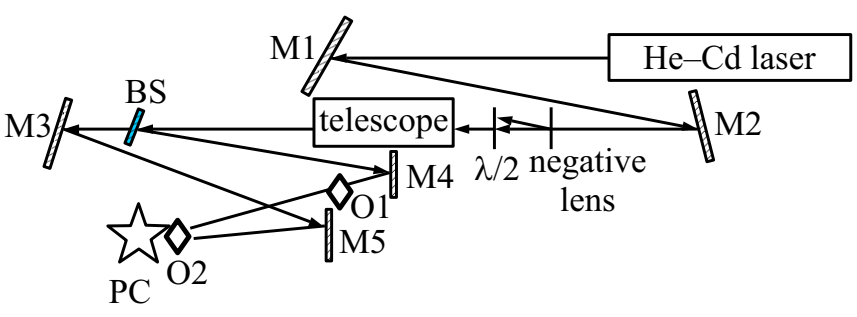

Рис. 1. Схема записи: M1, M2, M3, M4, M5 - зеркала; BS светоделительный кубик; $\lambda / 2$ - полуволновая пластинка; РC - нанокомпозитная регистрирующая среда; O1, О2 некоторые возможные положения объекта. 


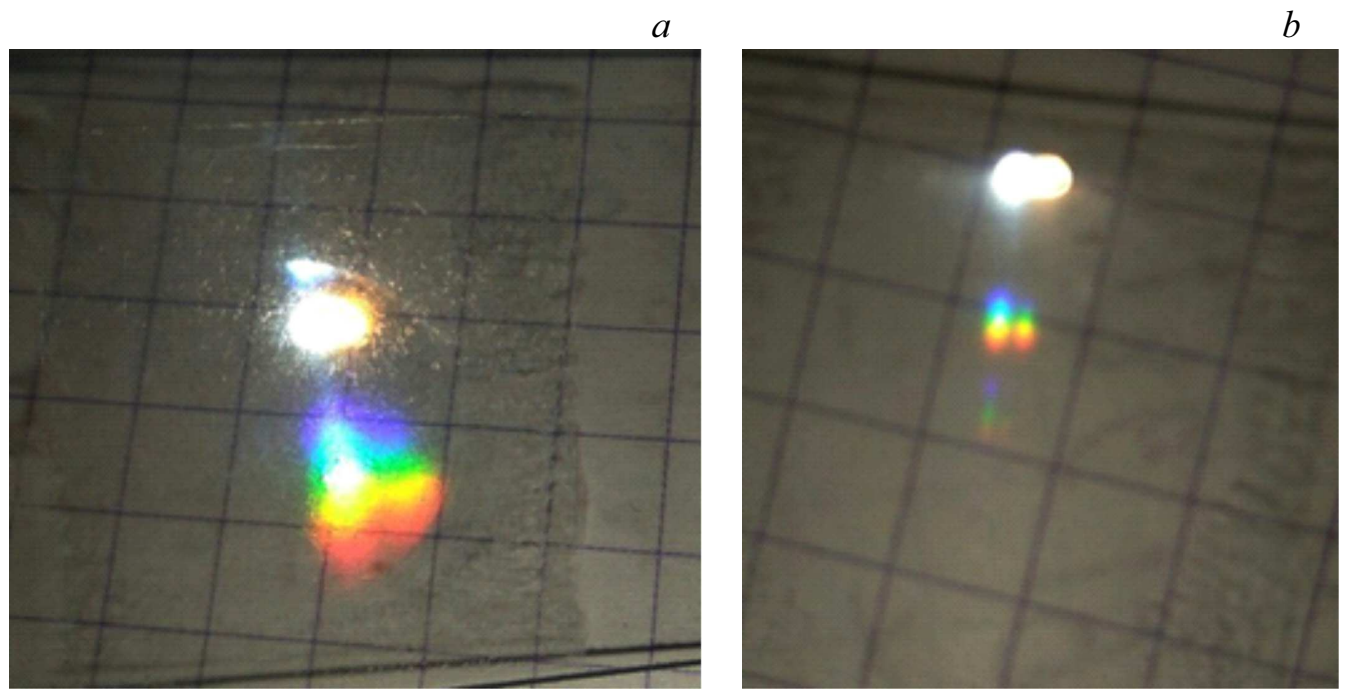

Pис. 2. Голограмма линзы, полученные с ее помощью увеличенное $(a)$ и уменьшенное $(b)$ изображения источника света.
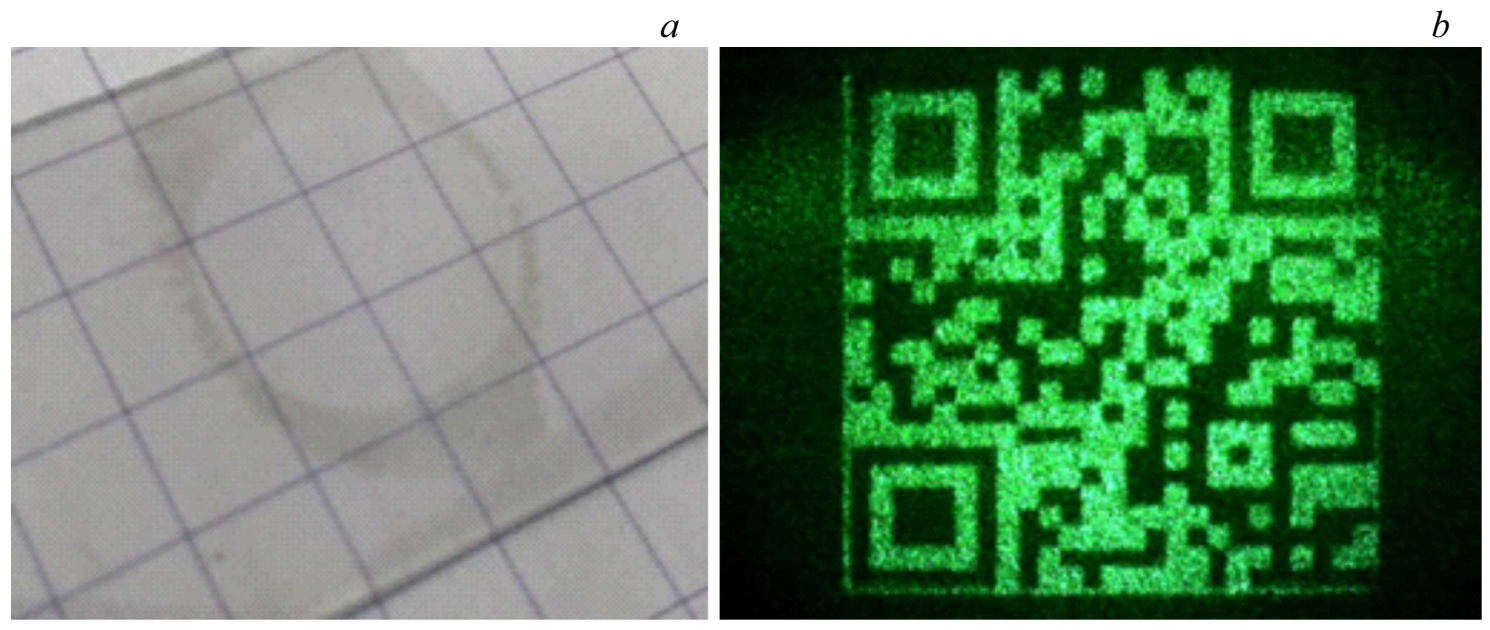

Рис. 3. Внешний вид образца материала с голограммой $(a)$ и считанное с голограммы криптографическое изображение $(b)$.

Запись голографических защитных элементов проводилась в попутных $s$-поляризованных пучках излучения одномодового одночастотного $\mathrm{He}-\mathrm{Cd}$ лазера с длиной волны $442 \mathrm{~nm}$, расположение объекта зависит от желаемого конечного результата (рис. 1). Толщина слоя нанокомпозита различных элементов варьировалась от 30 до $80 \mu \mathrm{m}$.

В результате были получены следующие элементы.

1. Пропускающая голограмма линзы (рис. 2). Полученный элемент записан на композиции 70 вес.\% 2 Car/30 вес.\% Bis, 6\% $\mathrm{SiO}_{2}-0.5 \%$ Irg. Элемент может работать как на увеличение, так и на уменьшение, что хорошо видно при его подсветке точечным источником излучения. Подобный элемент может быть дополнен графической информацией. Он будет работать аналогично рассмотренному ранее, но на него дополнительно нанесено изображение плоского объекта, что является визуально различимым криптографическим признаком.
2. Голограмма, содержащая не видимое глазом, скрытое криптографическое изображение (рис. 3); она записана на материале такого же состава, как и голограмма линзы. Данный элемент является трехмерной голограммой с высокой угловой селективностью. Такая голограмма может быть правильно восстановлена только светом, имеющим определенные характеристики (угол падения пучка, диаметр, расходимость, длина волны). При выполнении заданных условий освещения формируется машинно-читаемый QR-код.

3. Пропускающий элемент на основе объемной голограммы. Элемент записан непосредственно на бумажной подложке, сразу после нанесения композиции 10 вес.\% 2 Carb, 80 вес. $\%$ UDMA, 10 вес. $\%$ DIOL, $6 \% \mathrm{SiO}_{2}-0.5 \%$ Irg. Данный элемент может содержать произвольную информацию в виде рисунка или текста - личную подпись; его невозможно снять с бумажной подложки, не повредив сам элемент или бумагу (рис. 4). 


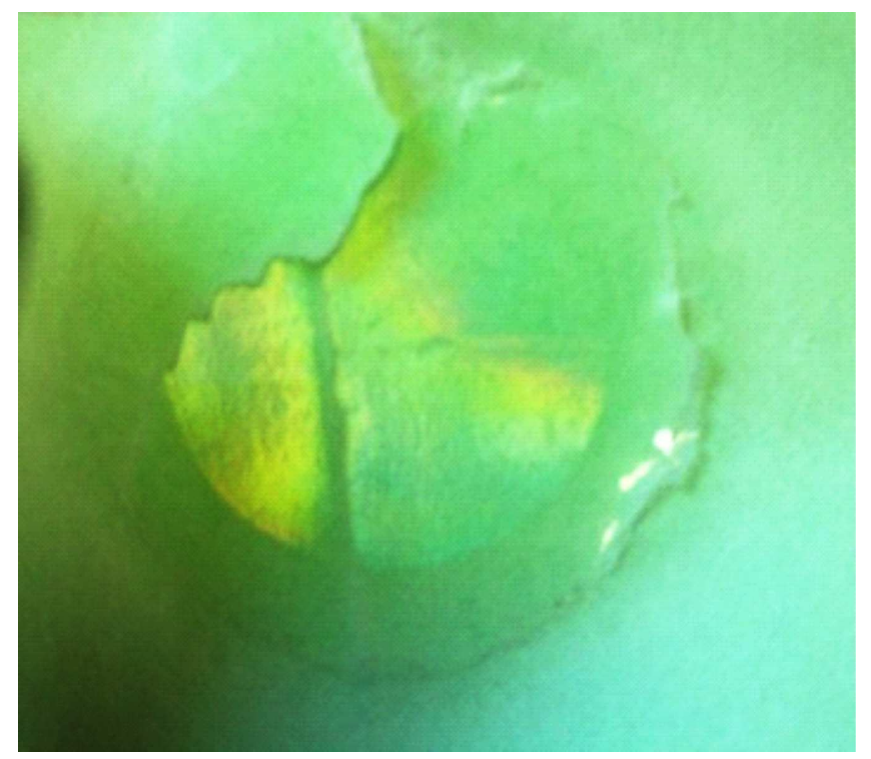

Рис. 4. Пропускающий элемент на основе объемной голограммы на бумажной подложке.

Проведены экспериментальные исследования возможности записи голографических защитных элементов на фоточувствительном нанокомпозите на основе акрилатных мономеров и неорганических наночастиц. Показано, что этот материал подходит для данных целей, запись возможна в видимой области на пленочной, бумажной или стеклянной подложке. Полученные элементы могут применяться в качестве персонифицированной, не копируемой защиты для ценных бумаг и документов, элементов, подтверждающих целостность упаковки, элементов голографических систем контроля и управления доступа.

Исследование выполнено при финансовой поддержке РФФИ в рамках научного проекта № 18-32-00861.

\section{Список литературы}

[1] Gleeson M.R., Sheridan J.T. // J. Opt. A: Pure Appl. Opt. 2009. V. 11. P. 024008 (12pp).

[2] Suzuki N., Tomita Y., Kojima T. // Applied Physics Letters. 2002. V. 81. P. 22.

[3] Денисюк И.Ю., Бурункова Ю.Э., Ворзобова Н.Д., Фокина М.И., Булгакова В.Г. // Патент РФ № 2541521. Бюл. 2015. № 5.

[4] Бурункова Ю.Э., Денисюк И.Ю., Фокина М.И., Жук Д.И. // Патент РФ № 2574723. Бюл. 2016. № 4.

[5] Burunkova J.A., Denisyuk I.Y., Zhuk D.I., Sheklanova E.B. // Opt. Spectrosc. 2017. V. 122. N 2. P. 341-343. 